\title{
Interventional and Interdisciplinary Endoscopy - Developments and Chances
}

\author{
Hans-Dieter Allescher ${ }^{a}$ Michael Hünerbein \\ a Zentrum Innere Medizin - Gastroenterologie, Hepatologie, Stoffwechsel, Nephrologie, Klinikum Garmisch-Partenkirchen, \\ Garmisch-Partenkirchen, Germany; \\ ${ }^{b}$ Klinik für Allgemein-, Viszeral- und Onkologische Chirurgie, HELIOS Klinikum Berlin-Buch, Berlin, Germany
}

Interventional endoscopy has developed substantially over the last 50 years. The replacement of the fiberoptic technique by highresolution video chips has changed and increased the diagnostic abilities of flexible endoscopy. Current technical innovations such as light supply with LEDs and miniaturized video chips will further amplify our endoscopy capabilities. Interventional procedures in the lumen and in the pancreaticobiliary system were boosted by technical advances and by the NOTES movement. Improved methods for luminal closure such as clipping and sutures opened the access to the submucosal space. New hemostatic devices and procedures made more invasive procedures feasible and safe. The borders to other neighboring medical disciplines, such as pulmonology, ENT and radiology, are becoming more permeable, and the interdisciplinary interaction is increasing $[1,2]$, which is due to the fact that the images generated by the different disciplines are more easily exchanged for a better diagnosis and treatment of our patients. Tracking and navigation as well as augmented reality can be offered in the experimental setting. The combination of interventional flexible endoscopy with laparoscopic visceral medicine offers new minimal invasive treatment methods and modalities. Both fields share some similar techniques, but require quite specialized individual training and expertise. Especially more advanced techniques such as endoscopic submucosal dissection (ESD), submucosal tunneling endoscopic resection (STER),or peroral endoscopic myotomy (POEM) not only require highly specialized techniques and expertise, but also call for quality control and standardized procedures and training. Thus the question for common training and certifications for specialized interventional endoscopy has to be raised.

This also raises the question, whether it is cost effective to have performed screening endoscopy by highly specialized and trained gastroenterologists or if this relatively focused technique could be delegated and performed by specialized screening 'colonoscopists'. This very controversial topic is discussed in this issue [3]. Further important aspects in current flexible endoscopy are the problem and control of hygiene [4] as well as quality control and documentation $[5,6]$. Recent data have raised concerns for interventional techniques e.g. in the biliary system, which have to be handled with utmost attention and care.

This issue of Visceral Medicine gives an overview on different topics of interventional and interdisciplinary endoscopy. It sheds light on the quality requirements and different technical advances as well as on the crucial problem of the reimbursement of new interventional techniques [7]. The Interdisciplinary Discussion completing this issue aims to give an overview how various aspects of interventional endoscopy, e.g. education, organization of clinical and ambulatory settings, interdisciplinary collaboration and reimbursement of new interventional endoscopic procedures, are handled in various European countries.

The editors of the current issue would be glad if the articles presented here will stimulate the further development and advancement of modern minimal invasive endoscopy and laparoscopic procedures.

\section{References}

1 Frieling T: The role of the endoscopist on the stroke unit. Visc Med 2016; DOI: 10.1159/000443656.

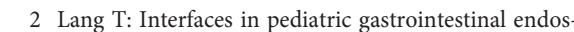
copy: who should do it? Visc Med 2016; DOI: $10.1159 / 000444116$.

$\checkmark 3$ Pfeifer UG, Schilling D: Non-physician endoscopy: how far can we go? Visc Med 2016; DOI: $10.1159 / 000443623$.
4 Jung M, Beilenhoff U: Hygiene: the looming Achilles heel in endoscopy. Visc Med 2016; DOI: 10.1159/000443626.

5 Denzer UW: Quality assurance in endoscopy: which parameters? Visc Med 2016; DOI: 10.1159/000443653.
Möschler O: Software tools in endoscopy - nice to have or essential? Visc Med 2016; DOI: 10.1159/000443628.

7 Wilke M-H, Rathmayer M: Reimbursement in endoscopy: how can new procedures be implemented? Visc Med 2016; DOI: 10.1159/000443652.

\section{KARGER \\ Fax +497614520714

\section{() 2016 S. Karger GmbH, Freiburg}

$2297-4725 / 16 / 0321-0006 \$ 39.50 / 0$
Prof. Dr. Hans-Dieter Allescher

Zentrum Innere Medizin - Gastroenterologie, Hepatologie, Stoffwechsel, Nephrologie Klinikum Garmisch-Partenkirchen

Auenstraße 6, 82467 Garmisch-Partenkirchen, Germany

Hans-Dieter.Allescher@klinikum-gap.de 